\title{
Raising Awareness About Social Exclusion in Schools Through Experiential
}

\section{Learning}

\author{
Erdem O. Meral ${ }^{1}$, Ilja van Beest ${ }^{1}$, Cana Karaduman ${ }^{2}$ \\ ${ }^{1}$ Department of Social Psychology, Tilburg University, Tilburg, the Netherlands \\ ${ }^{2}$ Department of Human Resource Studies, Tilburg University, Tilburg, the Netherlands
}

Draft version: 23 February 2022

This version of the manuscript is currently undergoing peer review. Comments are welcome.

\section{Author Note}

Erdem O. Meral, https://orcid.org/0000-0002-1825-0097

Ilja van Beest, http://orcid.org/0000-0003-2855-3638

Cana Karaduman

This research did not receive any specific grant from funding agencies in the public, commercial, or not-for-profit sectors. The current research evaluates a training program carried out by a non-profit organization. Any opinions expressed in this report are those of the authors and do not reflect the views of the non-profit in question. Authors indicate no further conflict of interest. Anonymized data and analysis scripts can be found on OSF (https://osf.io/bhrwx/).

Correspondence concerning this article should be addressed to Erdem O. Meral, Department of Social Psychology, Tilburg University, P.O. Box 90153, 5000 LE Tilburg, The Netherlands. E-mail: e.o.meral@tilburguniversity.edu. 


\begin{abstract}
Social exclusion has a myriad of negative effects on students' psychological and social wellbeing. One way to combat such negative effects is to raise awareness about social exclusion in schools. Here, we describe and evaluate a training program that was carried out across schools in the Netherlands. The program relies on basic experiential learning principles and a well-established social exclusion paradigm to make participants experience and discuss social exclusion. We had three goals in the current paper: (1) discussing previous work supporting the feasibility of such programs, (2) presenting a secondary analysis of the data generated by the program, and finally (3) testing a core assumption of Temporal Need-threat Model of Ostracism (Williams, 2009). The analyses are based on 14,065 participants (ages 12 to 19) and a subset of those who evaluated the program later $(n=386)$. Our review of the literature supports the feasibility of the program in raising awareness about social exclusion. The results of the secondary data analyses further corroborate this finding and, importantly, offer preliminary evidence for the effectiveness of the program. Lastly, stressing a core assumption of the ostracism model, the results indicated that the experience of ostracism was not substantially altered by the characteristics of the participants such as age and gender.
\end{abstract} Keywords: social exclusion, training program, experiential learning, awareness, the Netherlands 


\section{Raising Awareness About Social Exclusion in Schools Through Experiential Learning}

Social exclusion hurts, happens frequently (Nezlek et al., 2012) and is considered a risk factor for depression (Rudert et al., 2021). People experience its negative effects well into their adulthood (Rudert et al., 2020) and children are no exception (e.g., Elenbaas \& Killen, 2016). In fact, when it happens in schools social exclusion impacts students' social life and school adjustment negatively (Buhs \& Ladd, 2001) and is also a risk factor for psychological distress (Beeri \& Lev-Wiesel, 2012). One way to ameliorate the negative impact of experiences like social exclusion in schools is through raising awareness about the issue via intervention or training programs (e.g., Harrist \& Bradley, 2003; Leff et al., 2010). In the current paper, we present such a training program that is carried out by a Dutch nonprofit organization in schools across the Netherlands. This program aims to raise awareness about social exclusion. It is built as an experiential learning program and works by first making participants experience social exclusion with an online ball-tossing game. Next, participants engage in a guided discussion targeted at raising awareness and understanding amongst peers about social exclusion and its adverse effects.

We had three goals in presenting this training program. Our first goal was to discuss the theoretical background that guides the program (i.e., experiential learning: Kolb, 2014a) and material selections within the program to showcase the feasibility of such programs. Our second goal was to see how participants felt during the program and how they evaluated it by doing a secondary analysis of the data provided by the nonprofit organization. Finally, for our third goal we aimed to investigate a core assumption of a major model on social exclusion, namely the Temporal Need-Threat Model of Ostracism (Williams, 2007, 2009).

\section{Why Raise Awareness about Social Exclusion?}

We argue that programs focused on raising awareness on social exclusion are necessary for two main reasons. A first reason concerns the negative outcomes associated 
with being excluded. Being excluded has a negative influence on individuals' cognitive (Baumeister et al., 2002; Hawes et al., 2012; Wölfer \& Scheithauer, 2013), emotional (e.g., Hoglund et al., 2008; Leary, 2015; Prinstein \& Aikins, 2004; Wölfer \& Scheithauer, 2013), and social life (e.g., Buhs \& Ladd, 2001; Hoglund et al., 2008; Ladd, 2006). Some of these effects can also have long lasting consequences for the targets (i.e., persons that are excluded). For example, experiences of exclusion during adolescence can be traumatic for individuals and contribute to experiences of depression later during their childhood (Platt et al., 2013; Qualter et al., 2010) or young adulthood (Lev-Wiesel et al., 2006). Exclusion during school years can also have a long-lasting impact in terms of adjustment to school or society at large. For instance, children who are excluded or rejected during school years are more likely to engage in juvenile and adult criminality (Parker \& Asher, 1987), more likely to engage in substance abuse in adolescence and drop out of school (McDougall et al., 2001). Taken together, these studies highlight how social exclusion can have immediate and lasting negative effects on children in multiple aspects of their life. We believe that this persistent negative influence of social exclusion demonstrates the need for programs focusing on preventing such behaviors in schools.

A second reason why we argue that such training programs about social exclusion are crucial relates to the nature of social exclusion experiences. Social exclusion experiences are mostly subtle (Robinson et al., 2013; Robinson \& Schabram, 2017). This ambiguity surrounding the experience can in turn make social exclusion hard to recognize and deal with. More importantly, this subtlety may lead people to underestimate the adversity caused by social exclusion (e.g., O’Reilly et al., 2014). Therefore, we argue that raising awareness about social exclusion and helping individuals recognize exclusion and their part in it is a crucial part of navigating the potential hurt and negative outcomes associated with social exclusion. 


\section{Experiential Learning}

Lewis and Williams (1994, p. 5) describes experiential learning as "learning from experience or learning by doing." The main idea behind such learning is that students learn by going through an experience and then reflecting on the experience to develop a new perspective on the subject or learn new skills (Kolb, 2014a; Lewis \& Williams, 1994). In programs based on experiential learning the actual lived experience forms the basis for reflection. These reflections are then utilized to form conceptualizations and theories about the phenomenon (i.e., learning) which, in turn, guides the individual in creating new experiences (trying out what they learned or planning to try out). To summarize, a participant in an experiential learning program would build their knowledge through experiencing and reflecting on an experience, and in turn, this knowledge can be used to guide future actions surrounding the experience in question.

Experiential learning programs are used in various contexts such as workplaces (e.g., Baker et al., 2005; Heath et al., 2021), schools (e.g., Healey \& Jenkins, 2000; Konak et al., 2014), or in other institutions such as museums (e.g., Moorhouse et al., 2019) to facilitate learning. While it can be used to teach the content in a given subject matter (e.g., Leggette, 2012; Mahmoud \& Nagy, 2009), it can also be used to teach and raise awareness about social issues such as sexism (e.g., Cundiff et al., 2014) or bullying (e.g., Hall et al., 2009; Heath et al., 2021).

\section{Tackling Social Issues with Experiential Learning}

Similar to what we are doing in this paper, there are examples of previous work using (or suggesting the use of) experiential learning to raise awareness about social issues. For example, one such project uses a board-game like simulation in which participants have to advance in academic careers to increase to increase recognition of everyday sexism (Cundiff et al., 2014; Zawadzki et al., 2012). Another example focuses on cyberbullying and relies on 
participants' own experiences to discuss and raise awareness of cyberbullying (Chen, 2018). Yet another example aims to raise awareness of bullying among children and relies on a specific computer game to instill the experience (Hall et al., 2009). One last example targets workplace bullying and suggests that experiential learning can be used to raise awareness amongst managers to help ameliorate the problem of bullying in organizations (Heath et al., 2021). While some of these examples test the effectiveness of certain experiential learning programs (e.g., Chen, 2018; Cundiff et al., 2014; Hall et al., 2009; Zawadzki et al., 2012), some offer detailed explanations of a newly developed experiential learning program and advocates the use of it to tackle a certain social issue (e.g., Heath et al., 2021). Our approach in the current contribution falls between these two approaches. That is, while our focus is to illustrate how a tool to raise awareness about social exclusion can be developed (similar to the approach used by Heath et al., 2021), we also present preliminary evidence on whether such an approach is effective in reaching the goal of creating awareness about social exclusion.

\section{An Online Ball-Tossing game as the Concrete Experience}

Experiential learning programs aim to facilitate learning through experience. Therefore, to learn about social exclusion in such a program one first needs to feel excluded. In the program we describe here this was achieved via an online ball-tossing game. Since this game forms the basis of the program, we discuss some past research suggesting the suitability of this game for the training program. In this online ball-tossing game, participants play with several other simulated players and the amount of ball tosses received by the participant varies based on whether the participant is included or excluded. Excluded participants only receive the ball for the first few tosses and then do not receive the ball for the rest of the game. Included participants, however, receive an equal number of tosses as the other players. Versions of this online ball tossing game are widely used in social psychological research on 
social exclusion (e.g., van Beest et al., 2011; van Beest \& Williams, 2006; Williams et al., 2000) and the most popular one is called Cyberball (Williams \& Jarvis, 2006). A recent metaanalysis of 120 studies using this paradigm suggest that this paradigm is an effective way to induce feelings of exclusion across a wide range of outcomes and sampling aspects (such age and gender) $(d>|1.4|$ Hartgerink et al., 2015).

In the program we outline in this paper, a new version of the game was created to aid experiential learning. There were three important additions. First, the game was designed to be more engaging by adding a visual background and visual animations for characters (see Figure 1 for a screenshot from the game). Second, the game incorporated background music. Third, participants were allowed to choose how they wanted to be represented in the game by selecting an avatar out of six possible avatars. A crucial addition is that people not only saw their own avatars but also saw the avatars as chosen by other players with the name of the players on top of the avatars. Also relevant to note is that prior research on experiential learning has already shown that it is possible to implement mobile technologies and simulations to simulate the targeted experience (Hall et al., 2009; Lai et al., 2007; Leggette, 2012; Vannini et al., 2011). Hence, we think that the use of a well-established online balltossing game is an effective technique to use to induce feelings of exclusion in participants in training or intervention programs aiming to raise awareness about social exclusion via experiential learning. 


\section{Figure 1}

A visual from the version of the online ball tossing game used in the program.

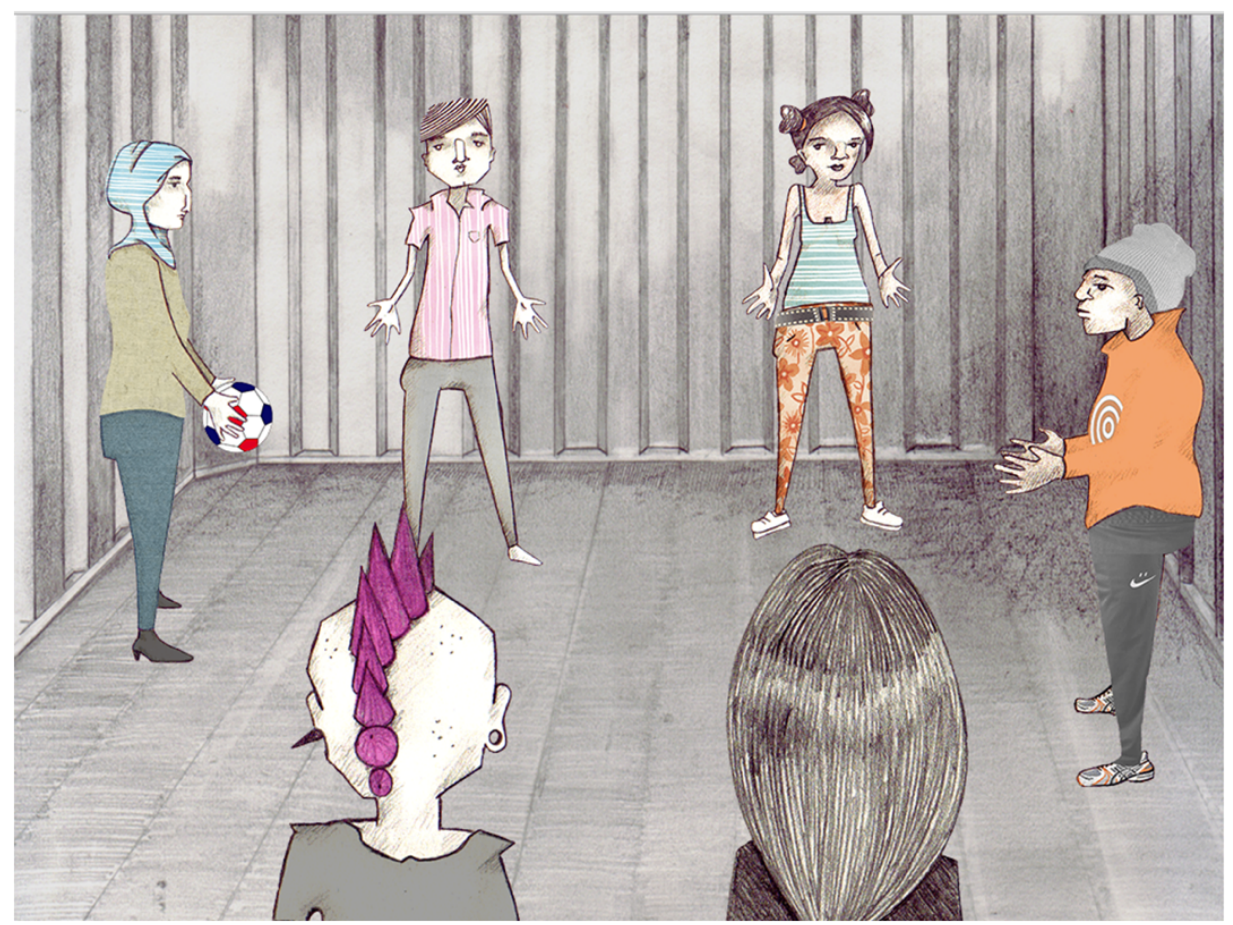

\section{Cross-cutting Factors}

A final goal in the current paper is to test a core assumption of a major model of social exclusion. According to the Temporal Need Threat (TNT) model of ostracism, the initial hurt of social exclusion is suggested to be impervious to cross-cutting variables (Williams, 2009). This is an ongoing field of inquiry and while some studies support this claim in terms of need threat (e.g., Gonsalkorale \& Williams, 2007; van Beest et al., 2011; Zadro et al., 2004), some others suggest that the immediate hurt of social exclusion may indeed be prone to moderation (e.g., Bernstein et al., 2010; Eck et al., 2017; Goodwin et al., 2010; van Beest et al., 2011). Previous investigations of cross-cutting factors incorporate factors such as gender (Hawes et al., 2012), age (Abrams et al., 2011; Pharo et al., 2011), size of the group in which the exclusion takes place (Hartgerink et al., 2015; Tobin et al., 2018), or race (Gonsalkorale \& Williams, 2007; Goodwin et al., 2010; Mulvey et al., 2016) to name a few. Therefore, we reported our results also in a way that could speak to this debate about 
the cross-cutting variables by testing whether age, gender, the selected avatar, or group size influences the extent to which participants experience need threat following exclusion.

Relevant to note is that the hypothesis that ostracism is not moderated by crosscutting variables is often tested in a context where people are both included and ostracized. Findings then show that a cross-cutting variable has less impact on the participants in the ostracism condition than in the inclusion condition. In the current context we could not make that comparison as the experimental learning is focused on how people deal with exclusion, it was not focused on how people deal with inclusion. Hence, our finding may or may not show that a cross-cutting variable moderated the experience of exclusion. However, it will not show whether this lack of moderation is stronger or weaker in the exclusion condition than the inclusion condition. Moreover, because we evaluate this core assumption within the context of an experiential training program involving 14,014 participants, we decided to test this assumption from the perspective of whether an effect has practical relevance and not whether an effect is statistically significant. In short, we decided to follow the advice of (Ferguson, 2009) and only consider statistically significant findings relevant if the associated effect size would be equal or greater than a Cohen's $d=0.41$ (or $r=.20$ ).

\section{Friend and Foe and Secondary Data Analysis}

The training program that we discuss below was developed by a Dutch non-profit organization (Critical Mass: https://www.criticalmass.nl). It is part of a larger project named Friend and Foe (original name in Dutch: Vriend en Vijand) by the same non-profit that uses exhibitions and multimedia games to raise awareness and provide insights on social exclusion but also prejudice, bullying, social influence, and conflict escalation. For the social exclusion part of this program the second author provided input based on previous work on social exclusion in social psychology (e.g., on how to induce feelings of social exclusion or how to measure the effects of social exclusion and so on). The final decisions in terms of the 
questions and the procedure were made by the non-profit organization and the overall framework of the program was designed by the organization as well.

The social exclusion program uses the process of experiential learning to raise awareness about social exclusion. Participants of the program first go through a simulation of social exclusion by playing an online game. This serves as the concrete experience and forms the basis for following discussions during the training. Next, participants fill out a questionnaire to start reflecting on their experience during the ball-tossing game and engage in a discussion session lead by a facilitator. This discussion is focused on stimulating thinking about the experience in depth and to help form a new perspective on social exclusion. A crucial part of this discussion is that participants also think and talk about how they would react in the future if they were socially excluded or observe someone being excluded. This final stage ensures that the participants leave the discussion by having a plan as to how they could implement this knowledge into their lives.

We obtained two data sets from the organization that carried out the program. One data set contains data from the ball-tossing game and how participants felt after the game (henceforth referred to as the game dataset). The second data set contains answers to a questionnaire asking participants to evaluate the multiple aspects of the training program and the trainers in general (henceforth referred to as the evaluation dataset). We first present findings from the game dataset that speaks to how participants felt after exclusion and the moderation hypothesis by cross cutting factors. Next, we present data from the evaluation dataset to highlight how we think the current program may be an effective adaptation of experiential learning principles to raise awareness about social exclusion. We share the anonymized versions of both data sets and our analyses scripts in an open, online repository (link: https://osf.io/bhrwx/?view_only=de5a73bad7d74cd8a6c2ba122e5e4cdc). 


\section{Methods}

\section{Participants}

The game dataset consisted of 18,855 participants at various ages (from 10 to $70+$ ). We took several steps to clean the data. First, we removed participants from sessions with less than three and more than six participants because the game can only be played with three to six players (removed $n=1054$, remaining 17,801). Second, upon communication with the non-profit organization, we learned that the data also included the test runs and the data from teachers who sometimes also played the game. To remove people who were not participants of the program (e.g., teachers) and the test runs we applied a conservative age restriction and limited the final data set to participants between and including the ages of 12 and 19. Twelve is the start age of secondary school in the Netherlands, and 19 is an age when most people would have finished secondary school. This left us with only the participants who indicated being between the ages of 12 and 19 (removed $n=24,38$ ). Third, we removed the participants who responded with insufficient effort. We relied on a very high or a ver low-intra-individual response variability score (IRV: Dunn et al., 2018) as an indication of responding with insufficient effort. Very low IRV scores indicate responding to all or most items with the same value. Very high IRV scores, on the other hand, indicate extreme variability in responses (e.g., giving the lowest possible score to two items and highest possible score to the other two items). We calculated the IRV on the main dependent variable (i.e., need threat measure with four items, see more information in the materials section) because this measure has both negatively and positively worded items and is our main outcome variable in the game dataset. Having a very low IRV score based on this measure would indicate giving the same score to items that are reverse-worded, i.e., no response variability. Whereas, having a very high IRV score would mean indicating the lowest rating (1) on two of the items and the highest rating (7) on the other two, i.e., extreme response variability. To approach the data 
cleaning conservatively, we removed participants who had both very high and very low IRV scores $(n=1298)$. We calculated the IRVs with the "careless" package in R (Yentes \& Wilhelm, 2021).

After these steps to clean the data, the final game dataset consisted of 14,065 participants (6775 male, 7243 female, and 47 unidentified). Participants ranged from 12 to 19 years old $(M=14.50, S D=1.98)$. See Figure 2 for a detailed breakdown of age groups.

Figure 2

Distribution of participants of the training program by age.

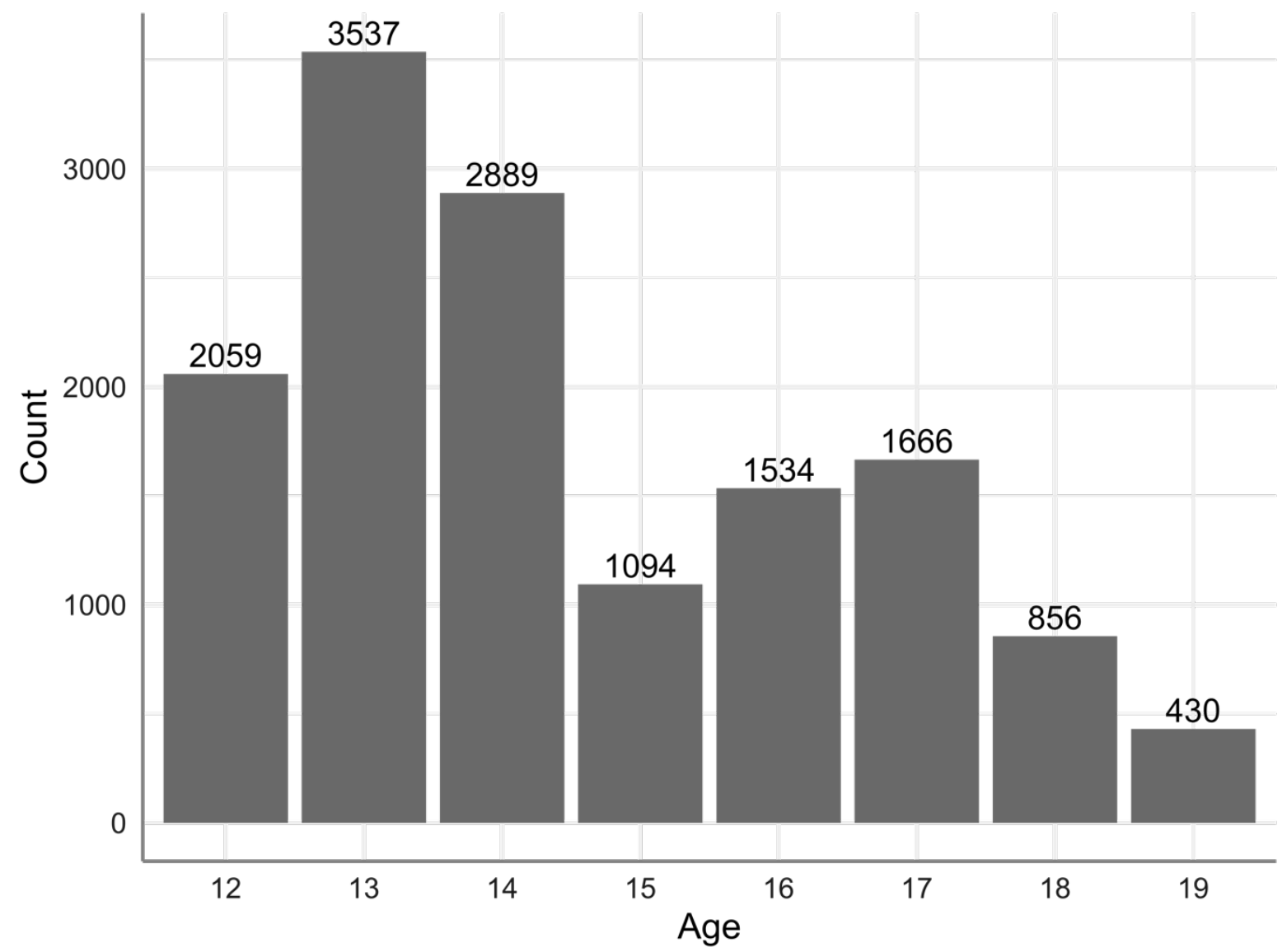

Note. The numbers above each bar indicate the number of participants for that age in the final sample.

The evaluation dataset consisted of a smaller group of participants $(N=384,238$ female, 146 male) who were asked to evaluate various aspects of the training program. The questionnaire did not include a question about participants' age yet included information on 
participants' school type and year. The inspection of school year data suggested that the evaluation data is limited to the first three years of secondary school in the Netherlands. Note that this would indicate that most of the students of the evaluation data set were aged 12 to and including 15 . Whereas our game data included students presumably from all levels of secondary school (class 1 till class 6) and thus included a range of students from 12 to and including 19.

\section{Procedure}

The Friend \& Foe project of Critical Mass visited high schools and placed five containers in the school yards ${ }^{1}$. One of these containers hosted the social exclusion program that we are discussing in the current paper. Participants entered the exclusion container in small groups ( 3 to 6 persons) and sat around a hexagon shaped table (See Figure 3 for a photo of from the inside of the said containers). There were panels on the table separating each participant from the rest. During the game, participants were asked to put on headphones. The headphones and panels served to limit the interaction amongst the participants and help them focus on the interaction in the game (to see how this setup looked, see Figure 3). After taking their seat at the table, participants first indicated their age, gender, and choice of avatar for the game. There were 3 male and 3 female avatars varying in hair styles and one avatar was wearing a hijab (see Table 1 for the pictures of the possible avatars). Next, all participants played the online ball-tossing game. In this game participants were led to believe that they were playing with their peers. Participants saw the names that their peers indicated as nicknames for themselves on top of the avatars they chose. Although participants saw the actual peers' avatars and names, the actual ball tosses in the game were pre-programmed such that all participants received the ball only for a couple times in the first few rounds and none

\footnotetext{
${ }^{1}$ Currently they are using an updated version of the ball-tossing game that can run on tablets and they mostly run this program in classroom environments. This reduces the overall costs of the training program and increases its accessibility.
} 
thereafter. In short, participants experienced that they were excluded by their peers during a game of ball toss. Afterwards, participants proceeded to answering questions assessing their immediate reaction to being excluded. Subsequently, participants were debriefed that the game was programmed to exclude everyone and that their classmates actually did not exclude them. Finally, participants watched a short video about the negative effects of social exclusion.

Figure 3

A photo from the inside of the social exclusion containers.

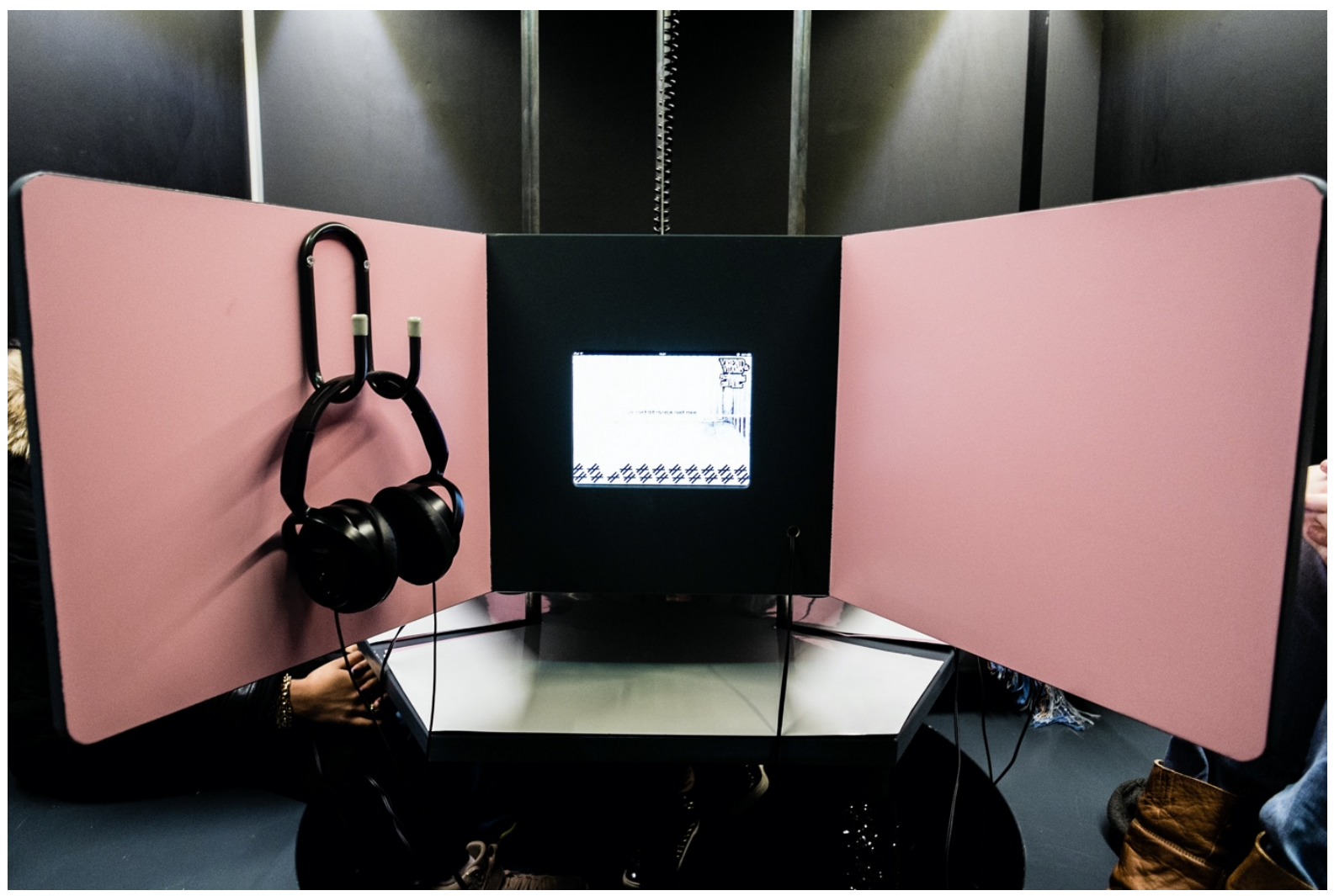

For the discussion session, the platform with the screen and panels ascended enabling participants to see each other again. At this stage, the facilitator presented the participants with discussion prompts focusing on the effects of social exclusion and how to react when one is excluded or when observes someone else being excluded. 


\section{Materials}

\section{Online ball-tossing game.}

The online ball-tossing game is an adapted version of Cyberball that is particularly designed for this program. The original version of Cyberball (Williams \& Jarvis, 2006) was purposefully designed in a minimal manner and it was devoid of detailed animations or music. This new version was designed to be more visually appealing and engaging (i.e., character and background animations and background music) and it had the option to choose an avatar. The avatar selections of each participant were visible to all the players. In the game screen all the avatars stand in a circle with the participants' avatar situated at the bottom left corner. When participants login to the game with their avatar and name, they saw other avatars on the screen with the names of their peers who are supposedly playing the game with them. To throw the ball around participants needed to click the avatar of another player's avatar (see Figure 1 for a visual depiction of this game). During the game participants were led to believe that they were playing the game with their peers, yet they all played the same pre-programmed version. In this version participants received two ball tosses in the beginning and none after. This ensured that each participant was excluded from the ball tossing game supposedly by their peers whom they were playing the game with. Playing this ball tossing game serves as the concrete experience mode of the experiential learning cycle (Kolb, 2014b).

\section{Reflection after the game.}

Experimental research on social exclusion typically uses the Need Threat Questionnaire (Williams, 2009) to measure the immediate effects of social exclusion. This measure assesses four separate psychological needs that are suggested to be impacted by social exclusion, namely, the need for belonging, meaningful existence, self-esteem, and control. In the current project participants indicated how they felt during the game by 
answering to one item per need (belonging: "I had the feeling that I was belonging during the game," meaningful existence: "I felt invisible during the game," self-esteem: "I felt good during the game," and control: "I had the feeling that I was the boss of the game."). Similar to previous work in the field (e.g., Riva et al., 2017; van Beest et al., 2011; Will et al., 2015; Williams et al., 2000), we combined these items into an overall index of need threat $(\alpha=.69)$. Higher numbers indicate more need threat. Feelings of anger following the game was also measured with a single item, "I felt angry during the game." The questions were presented individually in random order and were assessed on a 7-point Likert-type scale $(1=$ totally disagree, $4=$ neutral, 7 = totally agree) (see Appendix A for the original version of all items in Dutch). Relying on single-item measures of need threat and emotions in younger populations is not uncommon (e.g., Abrams et al., 2011). These need and emotion questions measure the immediate reaction of the participants to being excluded. In terms of the experiential learning cycle, these items serve as the reflective observation mode of the experiential learning cycle (Kolb, 2014b).

\section{Discussion after the game.}

The discussion section after the game focused on discussing the experience of the participants and how they would react if they were excluded in the future. Certain possible reactions were presented to the participants to prompt a conversation around what participants can do if they were excluded. These statements include "try not to think about it," "meet with other people," "stick up for yourself," "ask why you were excluded," "talk about it with friends or parents" (for a full list of items (both in English and Dutch), see appendix B). The discussion part was run by trained facilitators and it serves as the abstract conceptualization and active experimentation modes of experiential learning cycle (Kolb, 2014a). It serves as the abstract conceptualization mode because the participants discuss how they feel during the game to understand how it feels to be excluded. It serves the active 
experimentation stage because participants discuss different actions that they can take in the future if they were excluded or if they witness someone else being excluded. The non-profit organization did not gather any data pertaining to the discussion part. Therefore, we were not able to discuss the contents of the discussion phase any further.

\section{Evaluation of the program.}

A smaller group of participants also filled out a questionnaire to evaluate the program later $(N=384)$. This questionnaire included items measuring what participants thought of multiple aspects of the program. Here we assess questions that are specific to the social exclusion training but also questions about the overall program. There were three questions about social exclusion training which focused on whether participants gained new insights thanks to the program (e.g., "The exclusion container gave me insight."; $1=$ completely agree, $5=$ completely disagree). Moreover, there were also questions about the overall program such as questions about how specific parts of the program was perceived (e.g., "The discussion session was useful"), questions about the contents of the discussion section such as making plans to behave in a certain way in the future (e.g., "In the discussion session we made (new) agreements about how to treat each other), and questions tapping into behaviors following the program (e.g., "Did you talk about the program with your classmates"). Finally, there were questions about behaviors following the training program (e.g., "Since the program did you witness an unpleasant situation (such as exclusion or bullying etc.)," "Did you do anything differently at that time than you would have done before taking part in the program"). A full set of items can be found in Figures 4 and 5 (for the original version in Dutch, see Appendix C).

Note that we will assess a couple of questions that are not specific to the social exclusion program, but more general as they pertain to the evaluation of the overall program that was offered at schools. The other aspects of the overall program were also based on 
experiential learning and had the same structure but were focusing on other social issues (e.g., prejudice). We nevertheless decided to include the analysis of these more general questions in the current paper. The first reason why is that these general questions, albeit general, also speak to the specific event of the exclusion experience. The second reason is that some of questions touch upon the active experimentation phase of the learning cycle (e.g., whether they talked about the program with others or behaved differently following the program) and can be incorporated in the future uses of such programs. Therefore, we thought discussing these items would benefit the readers and future potential users of the program.

\section{Results}

We present the results in two subsections. In the first subsection we present our findings from both the game and the evaluation data that highlight why we think the current program using an online ball-tossing game is a good candidate for raising awareness about social exclusion. In this subsection we rely on descriptive statistics and data visualizations to present our data. In the second subsection we present findings from the game dataset as a test of the prediction that the initial hurt of social exclusion is impervious to cross-cutting variables (Williams, 2009) by testing how the said cross-cutting variables influence individuals' immediate reaction to being excluded.

Due to the large sample size of the game data set, we repeat our qualification mentioned in the general introduction that we will use evaluate effect sizes to interpret out findings (Cohen, 1969, 1998; Peeters, 2016, p. 22016; Sullivan \& Feinn, 2012). Following the advice of Ferguson (2009) we deemed a finding relevant if the effect size is equal or greater than Cohen's $d=.41$ (or $r=20$ ), and thus irrelevant if the effect size would be lower than Cohen's $d=0.41$ (or $r=20)$. 


\section{Preliminary Findings on the Training Program}

\section{How did participants feel after playing the game?}

Participants were asked to reflect on their experience in the social exclusion game by answering questions tapping into their need fulfillment and anger. We offer a secondary analysis of these answers. Since we did not have a control condition (e.g., an inclusion condition where all participants received equal ball tosses), we choose to present the descriptive statistics alongside a comparison of the mean values to the middle-point of the scale for need threat values similar to previous work (e.g., Sleegers et al., 2016). The results revealed that participants felt more need threat $(M=4.58, S D=1.35)$ than the middle-point of the used scale $(4), t(14,064)=51.15, p<.001, d=.43[.38, .50]$.

For feelings of anger, we did not compare the results to the midpoint (4) but instead to the lowest value on the scale (1). The reason is that feelings of anger are typically absent when people are included (i.e., hover around the lowest value of the scale) and comparing anger to the midpoint would thus be a too conservative test of whether exclusion induces anger (e.g., Rajchert et al., 2017; Svetieva et al., 2016; Zadro et al., 2004). The result of our comparison revealed that participants felt more anger $(M=2.53, S D=1.98)$ than the lowest value on the scale, $t(14,064)=91.35, p<.001, d=.77$.

\section{How did participants evaluate the social exclusion program?}

Did participants find the program useful and insightful? Figure 4 shows the distribution of responses to the questions assessing how people evaluated the exclusion training program. The questions can be categorized into three clusters. Items 1-3 represent what we call new insight about exclusion. Items 4-7 represent how students perceived the discussion session (i.e., referred to as the "debriefing lesson" in the items) and we call this cluster perceptions of the discussion section. Items 8-12 represent the contents of the discussion . 
For results about new insights about exclusion, one can look at the top three questions in Figure 4. The distribution of the answers suggests that on average majority of the students agreed with the program giving them new insights about exclusion or their role in exclusion (see the top section of Figure 4, items 1-3). Additionally, majority of the students found the discussion part nice, useful, and interesting (see middle section of Figure 4, items 4-7). Finally, the pattern of answers with regards to the contents of the discussion phase also suggests that majority of the students got to reflect on the situation in their classroom and also got a chance to link multiple social issues together such as social exclusion and prejudice (See the bottom section of Figure 4, items 8-12). It seems that more students disagreed with the statement indicating that they made agreements on how to interact with each other in the future (item 9), suggesting room for improvement in future versions of the program. 


\section{Figure 4}

Percentage of responses to questions assessing the usefulness of the program.

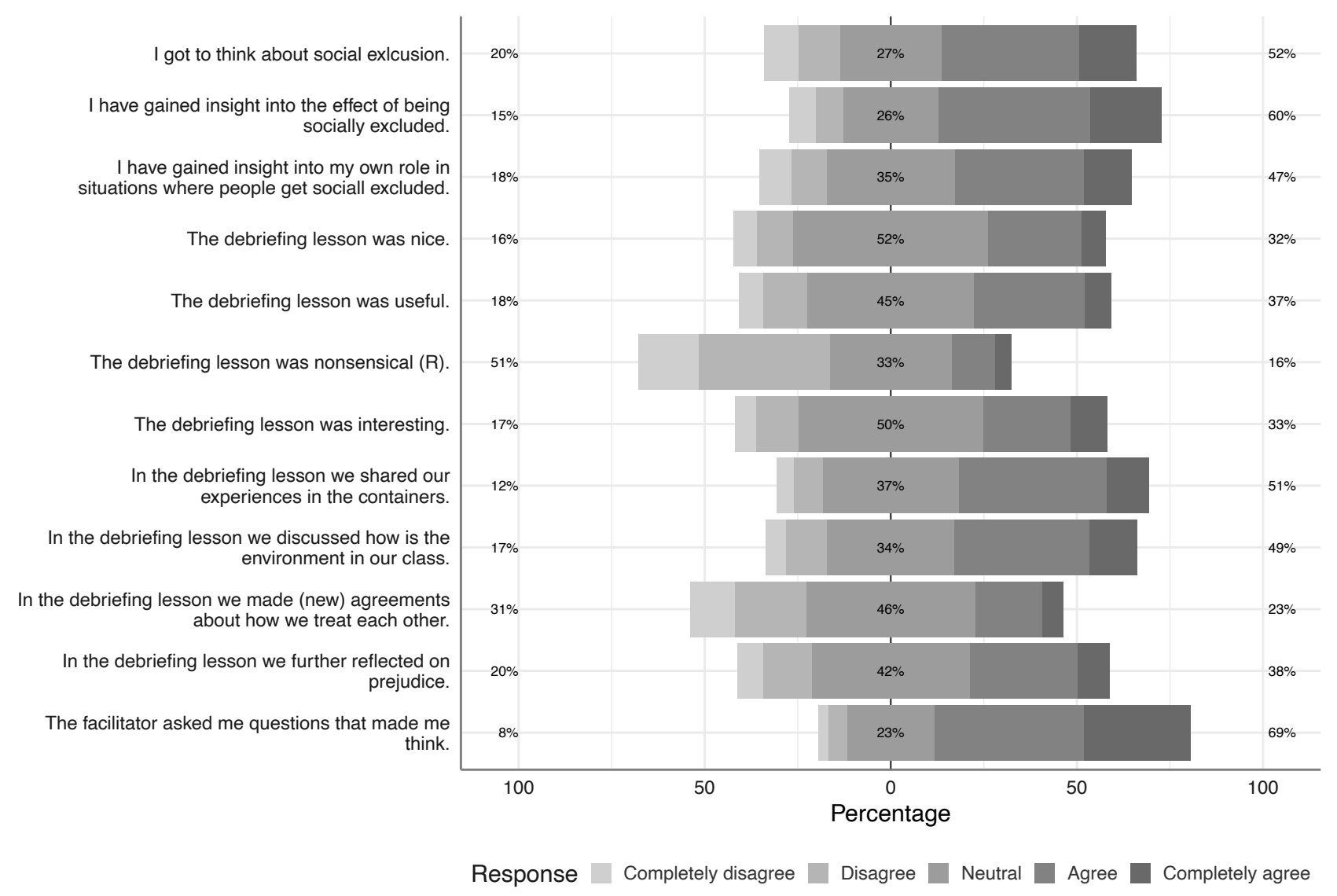

Note. The bars are centered around the neutral answer. On the right-hand side of the graph are the percentages of people who agreed (agree or completely agree) with a given item, and on the left-hand side are the percentages of people who disagreed (disagree or completely disagree). The percentages at the center reflect the people who choose the "neutral" option.

Did participants talk to others about the program? In Figure 5 depicts the distribution of responses assessing whether students talked about the program with classmates, family, and friends. The distribution shows that more than half of the participants talked about the program with their classmates (68\%) and with their families (67\%) at least 
one or more times. Moreover, more than one-third of the participants $(39 \%)$ reported talking about the program to their friends outside of the school.

\section{Figure 5}

Percentage of responses to questions assessing to whom participants talked about the program.

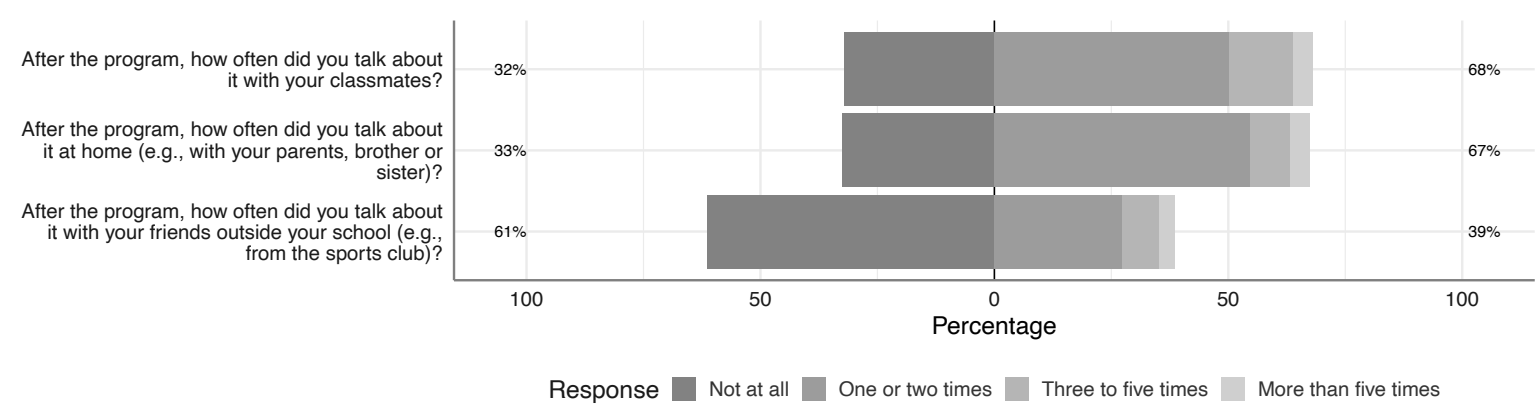

Note. The bars are centered around the point between "not at all" and "one or two times". Percentages of people who talked about the program with others at least "one or two times" are depicted on the right-hand side of the figure.

Did participants use what they learned from the program? Fifty-six participants indicated witnessing an unpleasant situation such as bullying or social exclusion (about 17\% of the total group of participants who evaluated the programs). Of these 56 participants 14 (25\%) indicated that they did something they would otherwise not have done before the program.

\section{Cross-cutting Variables}

\section{Does gender of the participant influence need threat?}

Participant gender affected the reported need threat after the game. Male participants reported lower need threat $(M=4.45 S D=1.44)$ than female participants, $(M=4.71, S D=$ 1.25), $t(13,464),=-11.64, p<.001, d=-.20,95 \%$ CI $[-.23,-.16]$. That is, female participants 
experienced more need threat (e.g., less belonging and control) than their male peers. Participant gender did not change reported anger, $t(13,700)=1.80, p=.07 d=.03,95 \% \mathrm{CI}$ $[.00, .06]$. Although statistically significant, the effect of gender on need threat falls short of what we deem practically significant in the current project $(d=.41$, Ferguson, 2009).

\section{Does age influence need threat?}

Participant age was statistically correlated with overall need threat $r=-.029, p<.001$, and anger $r=-.040, p<.001$. Note that both correlations are not practically relevant (i.e., $r<$ .20) and we would thus be hesitant to conclude that older participants in our sample are indeed less negatively affected by exclusion than younger participants.

\section{Does avatar choice influence need threat?}

Participants were able to select an avatar from a pool of 6 avatars (see Table 1, for descriptive statistics). One-way ANOVA's with six levels (avatars 1 to 6) showed that avatar selection had a significant effect on need threat, $F(5,14,059)=19.64, p<.001, \eta^{2}=.007$, and anger $F(5,14008)=5.36, p<.001, \eta^{2}=.002$; anger $F(5,14,059)=5.94, p<.001, \eta^{2}=$ .007 , and anger $F(5,14008)=5.36, p<.001, \eta^{2}=.002$. Due to the negligible effect sizes, we did not follow-up these effects with post-hoc analyses. 


\section{Table 1}

Selection of available avatars with corresponding descriptive statistics

\begin{tabular}{|c|c|c|c|c|c|c|}
\hline Avatar & 1 & 2 & 3 & 4 & 5 & 6 \\
\hline \multicolumn{7}{|l|}{ number } \\
\hline$n$ per avatar & 2218 & 2347 & 1762 & 2714 & 3856 & 1168 \\
\hline Need threat & 4.45 & 4.43 & 4.56 & 4.72 & 4.68 & 4.54 \\
\hline $\mathrm{M}(\mathrm{SD})$ & $(1.38)$ & (1.42) & $(1.44)$ & $(1.25)$ & $(1.25)$ & $(1.50)$ \\
\hline Anger & 2.45 & 2.52 & 2.64 & 2.51 & 2.47 & 2.77 \\
\hline $\mathrm{M}(\mathrm{SD})$ & (1.97) & $(2.01)$ & $(2.12)$ & (1.89) & $(1.90)$ & $(2.20)$ \\
\hline
\end{tabular}

\section{Does group size influence need threat and anger?}

Participants played the game in groups varying in size between 3 to 6 . We investigated whether the size of the group influenced need threat and anger. Group size was statistically correlated with overall need threat $r=-.027, p=.001$, and anger, $r=-.018, p=$ .03. Yet, similar to other cross-cutting variables we investigated, the size of the effect was again lower than our practical relevance threshold $(r=.20)$. Hence, we conclude that group size is not relevant for need threat and anger in this sample.

\section{General Discussion}

Social exclusion is a negative experience, yet its subtle and seemingly innocuous nature may cause it to fly under the radar (e.g., O'Reilly et al., 2014; Robinson \& Schabram, 2017). This may result in unnecessarily long suffering and long-term negative effects especially if individuals underestimate the negative influence that social exclusion has on individuals. Therefore, we think raising awareness about social exclusion in schools is crucial 
and can have a large impact if done early. The current article centers around a training program that did just that: raise awareness about social exclusion in schools. The specific program aims to raise awareness about antecedents and consequences of social exclusion, and it also aims to make students aware of the ways in which they can deal with social exclusion in the future (either as a target or as a bystander). We had three goals in presenting this program. First, we aimed to describe the program and its guiding principles. Second, we aimed to test whether this program can be useful by presenting a secondary analysis of the data that was generated within the program. Third, we aimed to test whether how participants feel after being excluded would be moderated by cross-cutting variables such as gender and age.

For our first goal, we described the training program and discussed the guiding principles behind the program to show how this program was theory- and research-driven in terms of its design and materials. Work on social exclusion, more specifically the work that incorporates Cyberball, shows that this online ball-tossing game is successful in inducing feelings of exclusion (Hartgerink et al., 2015). Work on experiential learning targeting social issues suggests that relying on experiential learning principles can indeed raise awareness about a variety of social issues such as bullying (e.g., Hall et al., 2009; Heath et al., 2021). More specifically, work on experiential learning shed lights on why the program we outline here was designed as such, and work on social exclusion informs why the specific paradigms and measures were incorporated (i.e., the online ball-tossing game and the associated measures). Taken together, we think that these two lines of work highlight two things. First, that experiential learning principles are a great fit for teaching about the subtle and usually underestimated experience of social exclusion. Second, that a well-studied paradigm for inducing the experience of social exclusion can also be utilized as a learning tool. 
For our second goal, we sought to test our theoretical reasoning about the usefulness of this program with a secondary data analysis. We analyzed the data that was provided to us by the non-profit organization which carried out the training program across schools in the Netherlands. This secondary analysis allowed us to evaluate how participants in the current sample felt after being excluded. Our results concerning need threat and anger revealed similar scores to that of other studies experimentally manipulating social exclusion with similar ball-tossing games (e.g., de Waal-Andrews \& van Beest, 2012; Sleegers et al., 2016; van Beest et al., 2011). We think this is an important contribution to the field for two main reasons. First, we think this similarity in findings supports the external validity of more controlled studies that use similar measures and paradigms. After all, our results are based on 14,014 school age participants across the Netherlands and show a similar pattern to those of more controlled lab studies. Second, we think this similarity is important because it provides a way for future versions of this training program to benefit from the extensive research that use similar measures and paradigms as we outlined here (see Hartgerink et al., 2015 for a meta-analysis of 120 studies using a similar ball-tossing game). For example, people who design future programs can enrich their training by studying the work on what aids recovery after being excluded in this ball-tossing game (e.g., Rudert et al., 2017; Zimmerman et al., 2021).

Importantly, this secondary analysis also allowed us to assess how a subgroup of participants in the current sample evaluated the program in terms of its content and usefulness. The majority of the participants in the evaluation dataset agreed that they gained insights into social exclusion, their role in social exclusion, and what they can do in such situations. Additionally, when evaluating the overall training program, most students also agreed that they had the chance to talk about the atmosphere in their classroom, and they indicated finding the debriefing sessions were useful and interesting. Given how social 
exclusion can be hard to recognize and underestimated (O'Reilly et al., 2014; Robinson \& Schabram, 2017), we think knowing more about the negative impact and one's part in inducing this negativity in others are essential. In fact, previous work shows committing inclusive behaviors in classrooms can have positive effects in terms reduced rates of peer rejection (Waasdorp et al., 2012) and more liking amongst peers (Harrist \& Bradley, 2003). Thus, we argue that teachers and practitioners can build on these new insights that their students gained to create more inclusive classrooms in which students are committed to more positive behaviors.

Active experimentation part of the experiential learning cycle focuses on taking the knowledge gained from the learning experience and carrying it out to the real world. Participants discussing this newly acquired information with others and recognizing the discussed issues in the real life can be taken as signs of active experimentation (Kolb, 2014b). Results based on a subset of participants who evaluated the program reveals some insights as to how participants may have carried this training program to their daily lives. Two-thirds of the participants indicated talking to their classmates or their family members about the program at least one or two times, and one-third indicated talking to their friends outside of school. This suggests that most participants may have taken the newly acquired knowledge outside of the learning contexts suggesting active experimentation. Importantly, a small portion of the participants $(17 \%)$ indicated witnessing a situation like the ones covered in the program (e.g., social exclusion and bullying). This presents the perfect opportunity for participants to apply whatever they learned from this program into their own lives. In fact, one-fourth of these participants indicated actually behaving in a way that they would not have done so before the training program. That is, some of the participants not only recognized a situation as social exclusion or bullying but also acted differently than they would have 
otherwise. We take this as further preliminary evidence for the usefulness of this program in raising awareness about social exclusion and similar social situations such as bullying.

Finally, for our third goal we tested the assumption of Temporal Need-Threat Model of Ostracism (Williams, 2009) that the immediate hurt of social exclusion is impervious to cross-cutting variables. Put differently, this model would assume that age, gender, group size and avatar choice should not moderate experienced need threat and anger. Our analyses provide mixed support for this core assumption. One the one hand, we provide statistical evidence that age, gender and avatar choice did moderate need threat (but not anger). However, the crucial issue here is that we had a very large sample, and that it thus important to account for that and thus rely on whether or not an effect has practical relevance instead of relying solely on the resulting $p$ values. From this perspective, the core assumption of the model is supported as neither age or gender, group size, or avatar choice moderated need threat or anger at the level it becomes practically relevant, a Cohen's $d=.41, r=.20$ (Ferguson, 2009).

Should then practitioners not care about these cross-cutting variables? We recommend otherwise. There is previous work that relies on a broader operationalization of both social exclusion (e.g., peer rejection) and reactions to social exclusion (e.g., distress or delayed responses) that shows moderation effects of variables such as age and gender (Beeri \& LevWiesel, 2012; Reijntjes et al., 2006). In the current paper we acknowledge these inconsistencies in the literature with regards to how people feel about social exclusion depending on certain characteristics. At the same time, we do not see this inconsistency in prior findings as a problem. After all, the training program does not only assess the immediate hurt, but it also includes a moment to actively discuss what happened to participants. This discussion is thus more attuned to reflection and prior research has provided consistent findings that upon reflection key cross-cutting variables to impact how 
people cope with the initial hurt of ostracism (e.g., Hartgerink et al., 2015; Ren et al., 2013; Yaakobi et al., 2021; Zadro et al., 2006). In other words, even though our analysis supports the Temporal Model of Ostracism (Williams, 2009) that the initial hurt is not substantially altered by cross-cutting variables, it is quite likely that they might when people are reflecting upon the experience. We thus recommend that, within the context of this program, the feeling of exclusion induced by the ball-tossing game should only be used as a steppingstone for future discussion. We suggest that when building upon these feelings of exclusion practitioners or researchers can think about the different ways in which this program can be adapted to the specific needs and characteristics of their target population. More specifically, we recommend relying on the large body of work investigating how people experience social exclusion or other relevant experiences (e.g., Smart Richman \& Leary, 2009; Wesselmann et al., 2016) based on their identity or group membership to enrich the program and make it more useful for their special use case (e.g., Beeri \& Lev-Wiesel, 2012; DeSouza et al., 2017, 2019; Goodwin et al., 2010; Hawes et al., 2012; Killen \& Stangor, 2001; London et al., 2012; Lopez \& DuBois, 2005; Mendoza-Denton et al., 2002).

\section{Limitations and Future Directions}

In the current contribution we integrated insights on experiential learning and insights on social exclusion. We presented data that participant found the experience valuable and that they learned from it. A possible limitation is that we did not test the effectiveness of our program in terms of the ability to reduce the actual occurrence of ostracism. This was beyond the scope of the collaboration that we had with the non-profit organization. We hope, however, that our first step will inspire future researchers or practitioners to test the effectiveness of this program in not only providing students with insight, but also in reducing actual rates of social exclusion in schools. 
In the program we focused only on the experience of being socially excluded. We did not focus on being socially included. This makes sense from the perspective of a training program carried out by a non-profit organization. Most studies relying on Cyberball to manipulate social exclusion compare the effects of an exclusion condition to an inclusion condition in which participants get an equal number of ball tosses. Such a comparison was out of scope for the current project. Yet, we reasoned that the descriptive statistics of need threat values could benefit from some comparison to values that would be obtained if there was an inclusion condition. To achieve that and to provide more context to otherwise difficult to interpret absolute values, we compared observed descriptive statistics on need threat to previous work also conducted in the Netherlands. We identified two such examples (de WaalAndrews \& van Beest, 2012; Sleegers et al., 2016) that use Cyberball and measure need threat with the 20-item Need Threat Questionnaire (van Beest \& Williams, 2006) that our questions were based on. In both studies, like the results presented here, the overall need threat scores were higher than the middle-point of the scale. We could not compare anger scores with these two studies because they do not report the results pertaining to anger separately as we do in this project. Yet work we used when making our analysis plan pertaining to anger shows similar values for levels of anger as we observe here (Rajchert et al., 2017; Svetieva et al., 2016; Zadro et al., 2004). Although we cannot compare the experience of being excluded to that of being included, we reasoned that discussing the descriptive statistics from other studies may help contextualize the absolute values we have and highlight that these scores are mostly in line with what one would observe studies with similar designs (and studies in a similar context, i.e., the Netherlands, in the case of need threat). 


\section{Conclusion}

Social exclusion is a negative experience, yet its innocuous nature may cause it to go under the radar. This may result in unnecessarily long suffering and may have long-lasting negative impacts on the targets of exclusion. One way to ameliorate these negative effects is to raise awareness about social exclusion in schools. To do so, we discussed a brief training program that integrated insights on experiential learning and social exclusion. We provide evidence that such a program can be devised. We also provide preliminary evidence suggesting that participants can gain relevant insights from such programs. We hope for this work to stimulate more researchers and practitioners to consider this combination and design and implement programs to combat the seemingly innocuous problem of social exclusion. 


\section{Reference}

Abrams, D., Weick, M., Thomas, D., Colbe, H., \& Franklin, K. M. (2011). On-line ostracism affects children differently from adolescents and adults. British Journal of Developmental Psychology, 29(1), 110-123. https://doi.org/10.1348/026151010X494089

Baker, A. C., Jensen, P. J., \& Kolb, D. A. (2005). Conversation as experiential learning. Management Learning, 36(4), 411-427. https://doi.org/10.1177/1350507605058130

Baumeister, R. F., Twenge, J. M., \& Nuss, C. K. (2002). Effects of social exclusion on cognitive processes: Anticipated aloneness reduces intelligent thought. Journal of Personality and Social Psychology, 83(4), 817-827. https://doi.org/10.1037/00223514.83.4.817

Beeri, A., \& Lev-Wiesel, R. (2012). Social rejection by peers: A risk factor for psychological distress. Child and Adolescent Mental Health, 17(4), 216-221. https://doi.org/10.1111/j.1475-3588.2011.00637.x

Bernstein, M. J., Sacco, D. F., Young, S. G., Hugenberg, K., \& Cook, E. (2010). Being “in” with the in-crowd: The effects of social exclusion and inclusion are enhanced by the perceived essentialism of ingroups and outgroups. Personality and Social Psychology Bulletin, 36(8), 999-1009. https://doi.org/10.1177/0146167210376059

Buhs, E. S., \& Ladd, G. W. (2001). Peer Rejection as an Antecedent of Young Children's School Adjustment: An Examination of.. Developmental Psychology, 37(4), 550. https://doi.org/10.1037//OO12-1649.37.4.550

Chen, C. W. (2018). "Think before you type": The effectiveness of implementing an anticyberbullying project in an EFL classroom. Pedagogies: An International Journal, 13(1), 1-18. https://doi.org/10.1080/1554480X.2017.1363046

Cohen, J. (1969). Statistical Power Analysis for the Behavioral Sciences (2nd ed.). 
Cohen, J. (1998). A power primer. Quantitative Methods in Psychology, 112(1), 155-159. https://doi.org/10.1037/0033-2909.112.1.155

Cundiff, J. L., Zawadzki, M. J., Danube, C. L., \& Shields, S. A. (2014). Using Experiential Learning to Increase the Recognition of Everyday Sexism as Harmful: The WAGES Intervention. Journal of Social Issues, 70(4), 703-721. https://doi.org/10.1111/josi.12087

de Waal-Andrews, W., \& van Beest, I. (2012). When you don’t quite get what you want: Psychological and interpersonal consequences of claiming inclusion. Personality and Social Psychology Bulletin, 38(10), 1367-1377. https://doi.org/10.1177/0146167212450463

DeSouza, E. R., Wesselmann, E. D., \& Ispas, D. (2017). Workplace Discrimination against Sexual Minorities: Subtle and not-so-subtle. Canadian Journal of Administrative Sciences, 34(2), 121-132. https://doi.org/10.1002/cjas.1438

DeSouza, E. R., Wesselmann, E. D., Taschetto, L. R., Rosa, G. C., Rosa, C. F. F., Yunes, M. A. M., da Silva, G. F., \& Fernandes, G. (2019). Investigating Ostracism and Racial Microaggressions Toward Afro-Brazilians. Journal of Black Psychology, 45(4), 222268. https://doi.org/10.1177/0095798419864001

Dunn, A. M., Heggestad, E. D., Shanock, L. R., \& Theilgard, N. (2018). Intra-individual Response Variability as an Indicator of Insufficient Effort Responding: Comparison to Other Indicators and Relationships with Individual Differences. Journal of Business and Psychology, 33(1), 105-121. https://doi.org/10.1007/s10869-016-9479-0

Eck, J., Schoel, C., \& Greifeneder, R. (2017). Belonging to a majority reduces the immediate need threat from ostracism in individuals with a high need to belong. European Journal of Social Psychology, 47(3), 273-288. https://doi.org/10.1002/ejsp.2233 
Elenbaas, L., \& Killen, M. (2016). Research in Developmental Psychology: Social Exclusion Among Children and Adolescents. In P. Riva \& J. Eck (Eds.), Social Exclusion: Psychological Approaches to Understanding and Reducing Its Impact (pp. 1-295). https://doi.org/10.1007/978-3-319-33033-4

Ferguson, C. J. (2009). An effect size primer: A guide for clinicians and researchers. Professional Psychology: Research and Practice, 40(5), 532-538. https://doi.org/10.1037/a0015808

Gonsalkorale, K., \& Williams, K. D. (2007). The KKK won't let me play: Ostracism even by a despised outgroup hurts. European Journal of Social Psychology Eur., 37, 11761186. https://doi.org/10.1002/ejsp.392

Goodwin, S. A., Williams, K. D., \& Carter-Sowell, A. R. (2010). The psychological sting of stigma: The costs of attributing ostracism to racism. Journal of Experimental Social Psychology, 46(4), 612-618. https://doi.org/10.1016/j.jesp.2010.02.002

Hall, L., Jones, S., Paiva, A., \& Aylett, R. (2009). FearNot! Providing children with strategies to cope with bullying. Proceedings of IDC 2009 - The 8th International Conference on Interaction Design and Children, 276-277. https://doi.org/10.1145/1551788.1551854

Harrist, A. W., \& Bradley, K. D. (2003). "You can't say you can't play”: Intervening in the process of social exclusion in the kindergarten classroom. Early Childhood Research Quarterly, 18(2), 185-205. https://doi.org/10.1016/S0885-2006(03)00024-3

Hartgerink, C. H. J., Van Beest, I., Wicherts, J. M., \& Williams, K. D. (2015). The ordinal effects of ostracism: A meta-analysis of 120 cyberball studies. PLOS ONE, 10(5), 124. https://doi.org/10.1371/journal.pone.0127002

Hawes, D. J., Zadro, L., Fink, E., Richardson, R., O’Moore, K., Griffiths, B., Dadds, M. R., \& Williams, K. D. (2012). The effects of peer ostracism on children's cognitive 
processes. European Journal of Developmental Psychology, 9(5), 599-613. https://doi.org/10.1080/17405629.2011.638815

Healey, M., \& Jenkins, A. (2000). Kolb's experiential learning theory and its application in geography in higher education. Journal of Geography, 99(5), 185-195. https://doi.org/10.1080/00221340008978967

Heath, M., Williams, E. N., \& Wynn, D. (2021). Experiential learning activity to ameliorate workplace bullying. Journal of Education for Business, 0(0), 1-15. https://doi.org/10.1080/08832323.2020.1858016

Hoglund, W. L. G., Lalonde, C. E., \& Leadbeater, B. J. (2008). Social-cognitive competence, peer rejection and neglect, and behavioral and emotional problems in middle childhood. Social Development, 17(3), 528-553. https://doi.org/10.1111/j.14679507.2007.00449.x

Killen, M., \& Stangor, C. (2001). Children's social reasoning about inclusion and exclusion in gender and race peer group contexts. Child Development, 72(1), 174-186. https://doi.org/10.1111/1467-8624.00272

Kolb, D. A. (2014a). Experiential Learning: Experience as the Source of Learning and Development (2nd ed.). FT Press.

Kolb, D. A. (2014b). The Process of Experiential Learning. In Experiential Learning: Experience as the Source of Learning and Development (pp. 32-63). FT Press. https://doi.org/10.4324/9780080517889-24

Konak, A., Clark, T. K., \& Nasereddin, M. (2014). Using Kolb's Experiential Learning Cycle to improve student learning in virtual computer laboratories. Computers and Education, 72, 11-22. https://doi.org/10.1016/j.compedu.2013.10.013

Ladd, G. W. (2006). Peer Rejection, Aggressive or Withdrawn Behavior , and Psychological Maladjustment from Ages 5 to 12: An Examination of Four Predictive Models Author 
(s ): Gary W. Ladd Published by: Wiley on behalf of the Society for Research in Child Development St. 77(4), 822-846.

Lai, C. H., Yang, J. C., Chen, F. C., Ho, C. W., \& Chan, T. W. (2007). Affordances of mobile technologies for experiential learning: The interplay of technology and pedagogical practices. Journal of Computer Assisted Learning, 23(4), 326-337. https://doi.org/10.1111/j.1365-2729.2007.00237.x

Leary, M. R. (2015). Emotional responses to interpersonal rejection. Dialogues in Clinical Neuroscience, 17(4), 435-441. https://doi.org/10.1093/acprof:oso/9780195130157.003.0006

Leff, S. S., Waasdorp, T. E., \& Crick, N. R. (2010). A review of existing relational aggression programs: Strengths, limitations, and future directions. School Psychology Review, 39(4), 508-535. https://doi.org/10.1080/02796015.2010.12087739

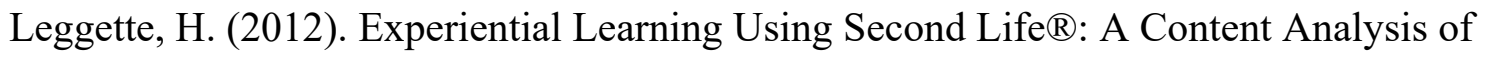
Student Reflective Writing. Journal of Agricultural Education, 53(3), 124-136. https://doi.org/10.5032/jae.2012.03124

Lev-Wiesel, R., Nuttman-Shwartz, O., \& Sternberg, R. (2006). Peer rejection during adolescence: Psychological long-term effects-A brief report. Journal of Loss and Trauma, 11(2), 131-142. https://doi.org/10.1080/15325020500409200

Lewis, L. H., \& Williams, C. J. (1994). Experiential learning: Past and present. New Directions for Adult and Continuing Education, 1994(62), 5-16. https://doi.org/10.1002/ace.36719946203

London, B., Downey, G., Romero-Canyas, R., Rattan, A., \& Tyson, D. (2012). Gender-based rejection sensitivity and academic self-silencing in women. Journal of Personality and Social Psychology, 102(5), 961-979. https://doi.org/10.1037/a0026615 
Lopez, C., \& DuBois, D. L. (2005). Peer victimization and rejection: Investigation of an integrative model of effects on emotional, behavioral, and academic adjustment in early adolescence. Journal of Clinical Child and Adolescent Psychology, 34(1), 2536. https://doi.org/10.1207/s15374424jccp3401_3

Mahmoud, A., \& Nagy, Z. K. (2009). Applying Kolb's Experiential Learning Cycle for Laboratory Education. Journal of Engineering Education, 98(3), 283-294. https://doi.org/10.1002/j.2168-9830.2009.tb01025.x

McDougall, P., Hymel, S., Vaillancourt, T., \& Mercer, L. (2001). The consequences of childhood peer rejection. In M. R. Leary (Ed.), Interpersonal Rejection (pp. 213-247). Oxford University Press.

Mendoza-Denton, R., Downey, G., Purdie, V. J., Davis, A., \& Pietrzak, J. (2002). Sensitivity to status-based rejection: Implications for African American students' college experience. Journal of Personality and Social Psychology, 83(4), 896-918. https://doi.org/10.1037/0022-3514.83.4.896

Moorhouse, N., tom Dieck, M. C., \& Jung, T. (2019). An experiential view to children learning in museums with Augmented Reality. Museum Management and Curatorship, 34(4), 402-418. https://doi.org/10.1080/09647775.2019.1578991

Mulvey, K. L., Palmer, S. B., \& Abrams, D. (2016). Race-Based Humor and Peer Group Dynamics in Adolescence: Bystander Intervention and Social Exclusion. Child Development, 87(5), 1379-1391. https://doi.org/10.1111/cdev.12600

Nezlek, J. B., Wesselmann, E. D., Wheeler, L., \& Williams, K. D. (2012). Ostracism in everyday life. Group Dynamics: Theory, Research, and Practice, 16(2), 91-104. https://doi.org/10.1037/a0028029 
O’Reilly, J., Robinson, S. L., Berdahl, J. L., \& Banki, S. (2014). Is negative attention better than no attention? The comparative effects of ostracism and harassment at work. Organization Science, 26(3), 774-793. https://doi.org/10.1287/orsc.2014.0900

Parker, J. G., \& Asher, S. R. (1987). Peer Relations and Later Personal Adjustment: Are Low-Accepted Children At Risk? Psychological Bulletin, 102(3), 357-389. https://doi.org/10.1037/0033-2909.102.3.357

Peeters, M. J. (2016). Practical significance: Moving beyond statistical significance. Currents in Pharmacy Teaching and Learning, 8(1), 83-89. https://doi.org/10.1016/j.cptl.2015.09.001

Pharo, H., Gross, J., Richardson, R., \& Hayne, H. (2011). Age-related changes in the effect of ostracism. Social Influence, 6(1), 22-38. https://doi.org/10.1080/15534510.2010.525852

Platt, B., Kadosh, K. C., \& Lau, J. Y. F. (2013). The role of peer rejection in adolescent depression. Depression and Anxiety, 30(9), 809-821. https://doi.org/10.1002/da.22120

Prinstein, M. J., \& Aikins, J. W. (2004). Cognitive Moderators of the Longitudinal Association Between Peer Rejection and Adolescent Depressive Symptoms. Journal of Abnormal Child Psychology, 32(2), 147-158.

Qualter, P., Brown, S. L., Munn, P., \& Rotenberg, K. J. (2010). Childhood loneliness as a predictor of adolescent depressive symptoms: An 8-year longitudinal study. European Child and Adolescent Psychiatry, 19(6), 493-501. https://doi.org/10.1007/s00787009-0059-y

Rajchert, J., Konopka, K., \& Huesmann, L. R. (2017). It is more than thought that counts: The role of readiness for aggression in the telationship between ostracism and 
displaced aggression. Current Psychology, 36(3), 417-427.

https://doi.org/10.1007/s12144-016-9430-6

Reijntjes, A., Stegge, H., \& Meerum Terwogt, M. (2006). Children's coping with peer rejection: The role of depressive symptoms, social competence, and gender. Infant and Child Development, 15(1), 89-107. https://doi.org/10.1002/icd.435

Ren, D., Wesselmann, E. D., \& Williams, K. D. (2013). Interdependent self-construal moderates coping with (but not the initial pain of) ostracism. Asian Journal of Social Psychology, 16(4), 320-326. https://doi.org/10.1111/ajsp.12037

Riva, P., Montali, L., Wirth, J. H., Curioni, S., \& Williams, K. D. (2017). Chronic social exclusion and evidence for the resignation stage. Journal of Social and Personal Relationships, 34(4), 541-564. https://doi.org/10.1177/0265407516644348

Robinson, S. L., O’Reilly, J., \& Wang, W. (2013). Invisible at Work: An Integrated Model of Workplace Ostracism. In Journal of Management (Vol. 39, Issue 1, pp. 203-231). https://doi.org/10.1177/0149206312466141

Robinson, S. L., \& Schabram, K. (2017). Invisible at Work: Workplace Ostracism as Aggression. In Research and Theory on Workplace Aggression (pp. 221-244). https://doi.org/10.1017/9781316160930.010

Rudert, S. C., Hales, A. H., Greifeneder, R., \& Williams, K. D. (2017). When silence is not golden: Why acknowledgment matters even when being excluded. Personality and Social Psychology Bulletin, 43(5), 678-692. https://doi.org/10.1177/0146167217695554

Rudert, S. C., Janke, S., \& Greifeneder, R. (2020). The experience of ostracism over the adult life span. Developmental Psychology, 56(10), 1999-2012. https://doi.org/10.1037/dev0001096 
Rudert, S. C., Janke, S., \& Greifeneder, R. (2021). Ostracism breeds depression: Longitudinal associations between ostracism and depression over a three-year-period. Journal of Affective Disorders Reports, 4(February), 100118.

https://doi.org/10.1016/j.jadr.2021.100118

Sleegers, W. W. A., Proulx, T., \& van Beest, I. (2016). The social pain of Cyberball: Decreased pupillary reactivity to exclusion cues. Journal of Experimental Social Psychology, 69, 187-200. https://doi.org/10.1016/j.jesp.2016.08.004

Smart Richman, L., \& Leary, M. R. (2009). Reactions to discrimination, stigmatization, ostracism, and other forms of interpersonal rejection: A Multimotive Model. Psychological Review, 116(2), 365-383. https://doi.org/10.1037/a0015250

Sullivan, G. M., \& Feinn, R. (2012). Using effect size — Or why the P value is not enough. Journal of Graduate Medical Education, 4(3), 279-282.

https://doi.org/10.4300/JGME-D-12-00156.1

Svetieva, E., Zadro, L., Denson, T. F., Dale, E., O’Moore, K., \& Zheng, W. Y. (2016). Anger mediates the effect of ostracism on risk-taking. Journal of Risk Research, 19(5), 614631. https://doi.org/10.1080/13669877.2014.1003320

Tobin, S. J., McDermott, S., \& French, L. (2018). The role of group size in reactions to ostracism and inclusion. Group Processes \& Intergroup Relations, 21(7), 1014-1033. https://doi.org/10.1177/1368430217702723

van Beest, I., \& Williams, K. D. (2006). When inclusion costs and ostracism pays, ostracism still hurts. Journal of Personality and Social Psychology, 91(5), 918-928. https://doi.org/10.1037/0022-3514.91.5.918

van Beest, I., Williams, K. D., \& van Dijk, E. (2011). Cyberbomb: Effects of being ostracized from a death game. Group Processes \& Intergroup Relations, 14(4), 581-596. https://doi.org/10.1177/1368430210389084 
Vannini, N., Watson, S., Dautenhahn, K., Enz, S., Sapouna, M., Wolke, D., Woods, S., Hall, L., Paiva, A., André, E., Aylett, R., \& Schneider, W. (2011). “FearNot!”: A computerbased anti-bullying-programme designed to foster peer intervention. European Journal of Psychology of Education, 26(1), 21-44. https://doi.org/10.1007/s10212010-0035-4

Waasdorp, T. E., Bradshaw, C. P., \& Leaf, P. J. (2012). The impact of schoolwide positive behavioral interventions and supports on bullying and peer rejection: A randomized controlled effectiveness trial. Archives of Pediatrics and Adolescent Medicine, 166(2), 149-156. https://doi.org/10.1001/archpediatrics.2011.755

Wesselmann, E. D., Grzybowski, M. R., Steakly-Freeman, D. M., DeSouza, E. R., Nezlek, J. B., \& Williams, K. D. (2016). Social exclusion: Psychological approaches to understanding and reducing its impact. In P. Riva \& J. Eck (Eds.), Social Exclusion: Psychological Approaches to Understanding and Reducing Its Impact (pp. 3-23). https://doi.org/10.1007/978-3-319-33033-4

Will, G. J., Crone, E. A., \& Güroğlu, B. (2015). Acting on social exclusion: Neural correlates of punishment and forgiveness of excluders. Social Cognitive and Affective Neuroscience, 10(2), 209-218. https://doi.org/10.1093/scan/nsu045

Williams, K. D. (2007). Ostracism. Annual Review of Psychology, 58, 425-452. https://doi.org/10.1146/annurev.psych.58.110405.085641

Williams, K. D. (2009). Ostracism: A temporal need-threat model. In M. P. Zanna (Ed.), Advances in Experimental Social Psychology (1st ed., Vol. 41, Issue 08, pp. 275314). Elsevier Inc. https://doi.org/10.1016/S0065-2601(08)00406-1

Williams, K. D., Cheung, C. K. T., \& Choi, W. (2000). Cyberostracism: Effects of being ignored over the Internet. Journal of Personality and Social Psychology, 79(5), 748762. https://doi.org/10.1037/0022-3514.79.5.748 
Williams, K. D., \& Jarvis, B. (2006). Cyberball: A program for use in research on interpersonal ostracism and acceptance. Behavior Research Methods, 38(1), 174-180. https://doi.org/10.3758/BF03192765

Wölfer, R., \& Scheithauer, H. (2013). Ostracism in childhood and adolescence: Emotional, cognitive, and behavioral effects of social exclusion. Social Influence, 8(4), 217-236. https://doi.org/10.1080/15534510.2012.706233

Yaakobi, E., Administration, B., \& College, O. A. (2021). Personality as a moderator of immediate and delayed ostracism distress. 1-27. https://doi.org/10.1111/bjso.12484

Yentes, R., \& Wilhelm, F. (2021). Package 'careless ': Procedures for computing indices of careless responding version. $1-11$.

https://doi.org/10.1016/j.jesp.2015.07.006>.License

Zadro, L., Boland, C., \& Richardson, R. (2006). How long does it last? The persistence of the effects of ostracism in the socially anxious. Journal of Experimental Social Psychology, 42(5), 692-697. https://doi.org/10.1016/j.jesp.2005.10.007

Zadro, L., Williams, K. D., \& Richardson, R. (2004). How low can you go? Ostracism by a computer is sufficient to lower self-reported levels of belonging, control, self-esteem, and meaningful existence. Journal of Experimental Social Psychology, 40(4), 560567. https://doi.org/10.1016/j.jesp.2003.11.006

Zawadzki, M. J., Danube, C. L., \& Shields, S. A. (2012). How to Talk about Gender Inequity in the Workplace: Using WAGES as an Experiential Learning Tool to Reduce Reactance and Promote Self-Efficacy. Sex Roles, 67(11-12), 605-616. https://doi.org/10.1007/s11199-012-0181-z

Zimmerman, C. A., Carter-Sowell, A. R., \& Ganesan, A. (2021). Confrontation as an interpersonal response to ostracism. European Journal of Social Psychology, 51(3), 436-449. https://doi.org/10.1002/ejsp.2749 


\section{Appendix B}

1. Ik had tijdens het spel het gevoel dat ik erbij hoorde (During the game, I felt like I belonged).

2. Ik voelde mij onzichtbaar tijdens het spel (During the game, I felt invisible).

3. Ik voelde me goed tijdens het spel (During the game, I felt good).

4. Ik had het gevoel dat ik de baas was over het spel (I had the feeling that I was the boss of the game).

5. "Ik voelde me boos tijdens het spel (During the game I felt angry). 


\section{Appendix C}

Discussion statements following the exclusion game. Students use these possible reactions and discuss what they could do in case they witness exclusion. Items are presented in Dutch (in their original form) and the English translations are presented within parentheses.

1. Er niet aan proberen te denken (You could try not to think about it).

2. Met andere mensen omgaan (You could simply start hanging out with other people).

3. Van je af bijten (You could stick up for yourself).

4. Hulp vragen aan leerkracht/iemand in je omgeving (You could ask for help from a teacher/someone around you).

5. Erover praten met vrienden en/of ouders (You could talk about it with friends and/or parents).

6. Vragen waarom je wordt buitengesloten (You could ask why you were left out). 


\section{Appendix C}

Items from in Figure 4 appearing in the same order as the figure in the original version (in Dutch).

1. Ik ben aan het denken gezet over buitensluiting.

2. Ik heb inzicht gekregen in het effect van buitensluiting.

3. Ik heb inzicht gekregen in mijn eigen rol in situaties voor mensen worden buitengesloten.

4. De nabespreking les was leuk.

5. De nabespreking les was nuttig.

6. De nabespreking les was onzinnig.

7. De nabespreking les was interessant.

8. In de nabespreking les hebben we onze ervaringen in de containers gedeeld.

9. In de nabespreking les hebben we besproken hoe de sfeer in onze klaas is.

10. In de nabespreking les hebben we (nieuwe) afspraken gemaakt over hoe we met elkaar omgaan.

11. In de nabespreking les hebben we verder nagedacht over vooroordelen.

12. De begeleider stelde vragen waardoor ik aan het denken gezet.

The original versions (in Dutch) of items in Figure 5 appearing in the same order as the figure.

1. Na de expeditie [Hoe vaak heb je het er met klasgenoten over gehad?]

2. Na de expeditie [Hoe vaak heb je het er thuis over gehad (met bijv. je ouders, broer of zus)?]

3. Na de expeditie [Hoe vaak heb je het er met vrienden buiten school (bijv. van de sportclub) over gehad?] 